\title{
Recommendations for Endovascular Care of Stroke Patients
}

\author{
Michelle Hill ${ }^{a}$ Brenda A. Glenn ${ }^{b}$ Brenda J. Reese ${ }^{a}$ Benjamin Morrow ${ }^{c}$ \\ a Riverside Methodist Hospital, Columbus, OH, bWellStar Kennestone Hospital, Marietta, GA, \\ and ' University of Pittsburgh Medical Center, Pittsburgh, PA, USA
}

\section{Keywords}

Acute stroke · Endovascular stroke therapy · Endovascular treatment · Neuromonitoring ·

Stroke thrombectomy

\begin{abstract}
The field of neurointerventional radiology (NIR) therapy, including acute ischemic stroke intervention, endovascular intracranial aneurysm management, and treatment of intra- and extracranial large-vessel disease, has evolved over the past 18 years. To support this specialized advanced care requires nursing standards of care for staff to provide direct patient care in NIR suites and intensive management of this high-risk patient population. The intent of this paper is to provide a complementary document for the Stroke Interventional Laboratory Consensus (SILC) statement that will specifically address the nursing standards of care for patients in an NIR suite.

(c) 2017 S. Karger AG, Basel
\end{abstract}

\section{Introduction}

The field of neurointerventional radiology (NIR) therapy, including acute ischemic stroke intervention, endovascular intracranial aneurysm management, and treatment of intra- and extracranial large-vessel disease, has evolved over the past 18 years. To support this specialized advanced care, nursing standards of care for staff that provide direct patient care in NIR suites and intensive management of this high-risk patient population are proposed in this document. 
Table 1. Patient conditions treated in the neurointerventional radiology suite

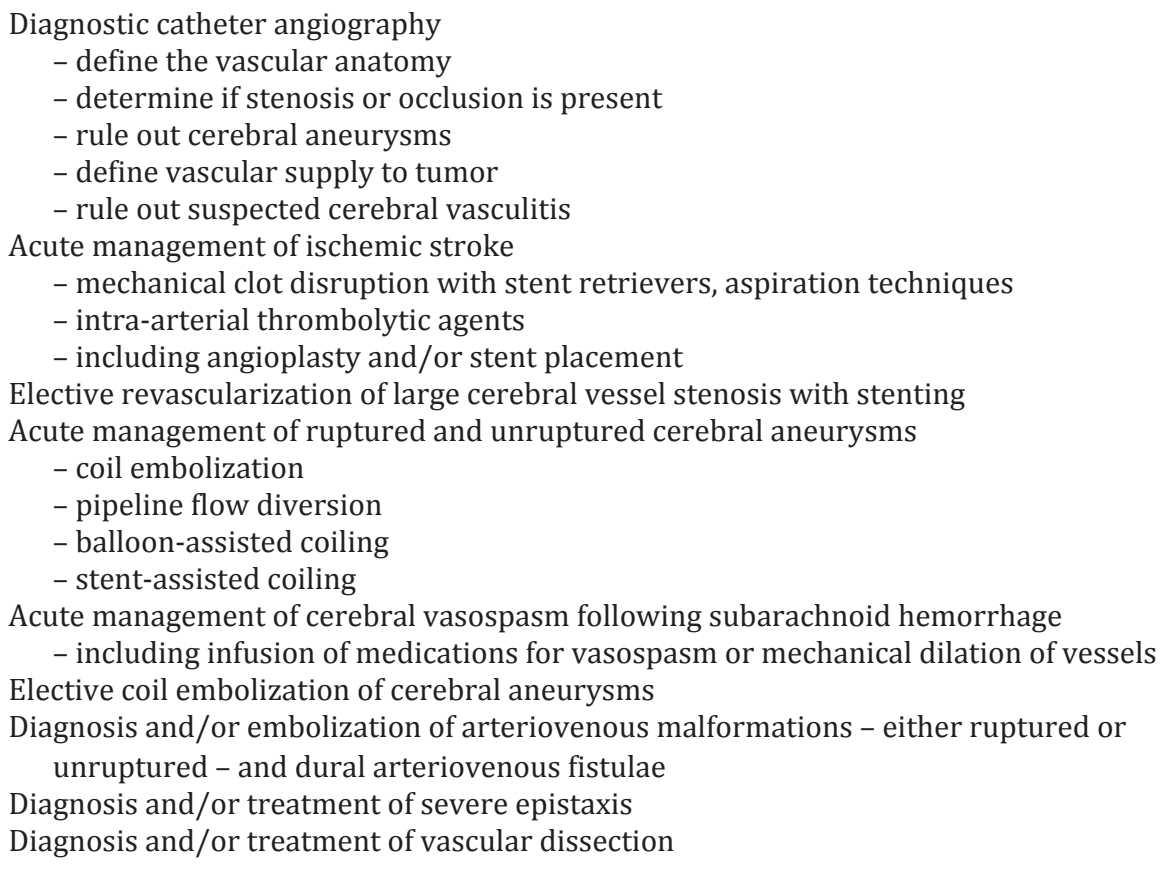

In 2014-2015, five large international clinical research trials of acute ischemic stroke compared IV tissue plasminogen activator (tPA) as the standard of care with endovascular treatment in conjunction with IV tPA for large-vessel occlusion in select patients, and were published in the New England Journal of Medicine. These studies individually and collectively demonstrated improved outcomes for patients who undergo acute endovascular treatment for large-artery occlusions, and this was subsequently recommended by the American Heart Association/American Stroke Association [1-6]. Concurrently, the treatment approaches for both ruptured and unruptured cerebral aneurysms have evolved, and scientific recommendations include endovascular as well as surgical approaches for definitive treatment $[7,8]$. The recommendations for the treatment of both symptomatic and asymptomatic carotid stenosis also have evolved and now include endovascular carotid artery stenting as well as carotid endarterectomy as treatment options [9].

There are a variety of both acute and non-acute patient conditions that are treated in the NIR suite (Table 1). In this document, we propose recommendations for structuring the staffing and care for this high-risk patient group while in the neurointerventional laboratory. This document includes recommendations for staff qualifications, staffing models, data collection, periprocedural assessment and care of the patient, groin/access management, common complications, and transition of care in the periprocedural handoff situations.

\section{Staffing Models in the NIR Suite}

Staffing models will vary depending on the institution, availability and/or requirement of anesthesia, and volume of after-hours cases. Academic institutions will often have neurointerventional fellows who are able to assist the interventionalist. In private hospital settings, 
Table 2. Neurointerventional radiology suite staffing models

\begin{tabular}{lll}
\hline & Academic setting & Private hospital setting \\
\hline Day shift & 1 circulating RN & 1 circulating RN \\
& 1 sedation RN or anesthesia team & 1 sedation RN or anesthesia team \\
& 1 IR technologist & 1 IR technologist \\
& 1 endovascular fellow & 1 IR scrub technologist \\
& 1 attending physician & 1 attending physician \\
\hline Call at night & Anesthesia team & 1 sedation RN or anesthesia team \\
& 1 circulating RN & 1 circulating RN \\
& 1 IR technologist & 1 IR technologist \\
& 1 endovascular fellow & 1 attending physician \\
& 1 attending physician & \\
\hline
\end{tabular}

RN, registered nurse; IR, interventional radiology.

the interventional radiology technologist will often be scrubbed in with the physician and serve as the first assistant on the case. Suggested staffing models for NIR room coverage for academic and private hospital settings are listed in Table 2.

\section{Role of the Registered Nurse and Radiology Technologist}

The registered nurse (RN) is an essential component of the neurointerventional team. The nursing and technologist responsibilities for neurointerventional procedures are similar to the duties performed by nurses and technologists in interventional radiology and cardiac interventional laboratories. The NIR nurse is assigned the role of either the circulating nurse or the conscious sedation nurse; the radiology technologist can also be assigned the role of circulator. Regardless of the position assigned, the role of the nurse and technologist in the NIR suite is to provide optimal patient safety.

The primary function of the circulator role is to ensure fluidity of the case. This is made certain by thorough examination, detailed documentation, point-of-care testing (POCT), and providing the interventionalist with the tools needed throughout the case. If the circulator role is assigned to the technologist, the neurologic assessment will be performed by the sedation nurse.

The primary difference between an NIR nurse and a general interventional radiology nurse is the ability to perform a detailed neurologic examination as defined by the organization. The circulator will be responsible for assessing the patient before and after the procedure if the procedure is scheduled with anesthesia. If the case does not require the presence of an anesthesiologist, the responsibility for pre- and postprocedural examination will be with the conscious sedation nurse.

Through certification and experience, the nurse will be able to pick up subtleties that indicate a change in neurologic status that may influence the patient's outcome. Should a complication occur during the procedure, the pre- and postprocedural examination could identify its severity. In addition, quick notification of the physician of changes in examination results will lead to faster response times for further intervention, potentially improving outcomes. The NIR nurse should also be experienced and proficient in caring for patients during emergent neurologic events such as the need for urgent external ventricular drain 
(EVD) placement or an acute intracranial pressure (ICP) crisis. These skills would include the ability to deliver hyperosmolar therapy and emergent blood pressure control management in an acute emergency.

The circulator is responsible for detailed documentation throughout the case. While this aspect of the job may seem tedious, the documentation includes extremely important data used in outcome measurements. In the field of vascular neurology, time is of the essence in the majority of cases. When dealing with acute ischemic stroke, documenting groin puncture, clot retrieval, and reperfusion times can provide accurate retrospective data to help identify opportunities to improve the procedural process and reduce treatment durations.

Specific documentation points to consider in NIR cases are the following:

- Time in the room

- $\quad$ Preprocedural examination (National Institutes of Health Stroke Scale [NIHSS] score)

- Start of anesthesia or intubation time

- Groin puncture time

- Initial Thrombolysis in Cerebral Infarction (TICI) score

- Time of completion of each pass and TICI score after each pass

- Device deployment (i.e., stents/stent retriever/aspiration device/coils/balloons)

- Implant information (lot numbers/serial numbers/size of implant/location of implant)

- Medications administered intra-arterially by the surgeon

- $\quad$ POCT information (activated clotting time [ACT]/VerifyNow)

- Intakes and outputs (heparin flush/contrast)

- Time successful reperfusion is achieved

- Closure device (time of deployment/type)

- Postprocedural examination

The circulator is responsible for running POCT when directed by the physician. POCT typically includes ACT (heparin) and VerifyNow (P2Y12, glycoprotein IIb IIIa inhibitors, and acetylsalicylic acid). Being proficient with these forms of testing will assist the interventionalist in completing the case as safely as possible. Providing the interventionalist with accurate results will determine if additional anticoagulant therapy is required prior to deployment of stents or flow diverters or angioplasty.

The circulator should be proficient in the devices and products used in the NIR suite. Just as in the operating room, the circulator is expected to obtain products that are needed throughout the procedure and provide the interventionalist with them. Quick retrieval of products can positively influence the time to recanalization and hopefully improve outcomes. From shorter anesthesia duration to decreased time to reperfusion of the brain, a speedy response to the interventionalist's needs can result in better outcomes and improve patient safety.

The sedation nurse is responsible for providing conscious sedation and monitoring the patient in the absence of anesthesia personnel. Nurses in this capacity should be certified via the institutional protocol to administer conscious sedation. When a nurse is placed in this role, it must be the only responsibility assumed by that person [10-12]. The conscious sedation nurse will work in conjunction with the circulator. Similar to when anesthesia personnel are involved in a case, theirs is a single defined role; the conscious sedation nurse should function in the same manner. It is imperative for patient safety that the conscious sedation nurse remains at the patient's bedside and does not assume the responsibilities of a circulator. The nurse should also be familiar with agents to reverse sedative medications if indicated.

Before the procedure, the conscious sedation nurse should review the patient's history, allergies, and prescribed medications. Assessments include preprocedural examinations, review of the laboratory work, and ensuring NPO status. Any deviations or concerns should 
Table 3. American Society of Anesthesiologists (ASA) classification

\begin{tabular}{ll}
\hline ASA classification & Definition \\
\hline ASA class I & A normal healthy patient \\
ASA class II & A patient with mild systemic disease \\
ASA class III & A patient with severe systemic disease \\
ASA class IV & A patient with severe systemic disease that is a constant threat to life \\
ASA class V & A moribund patient who is not expected to survive without the operation \\
ASA class VI & A declared brain-dead patient whose organs are being removed for donor purposes \\
\hline
\end{tabular}

Table 4. Mallampati classification

$\begin{array}{ll}\text { Class } 0 & \text { Ability to see any part of the epiglottis upon mouth opening and tongue protrusion } \\ \text { Class I } & \text { Soft palate, fauces, uvula, pillars visible } \\ \text { Class II } & \text { Soft palate, fauces, uvula visible } \\ \text { Class III } & \text { Soft palate, base of uvula visible } \\ \text { Class IV } & \text { Soft palate not visible at all }\end{array}$

Table 5. Continuum of depth of sedation: definition of general anesthesia and levels of sedation/analgesia

\begin{tabular}{lllll}
\hline & $\begin{array}{l}\text { Minimal } \\
\text { sedation } \\
\text { (anxiolysis) }\end{array}$ & $\begin{array}{l}\text { Moderate sedation/ } \\
\text { analgesia } \\
\text { (conscious sedation) }\end{array}$ & $\begin{array}{l}\text { Deep sedation/ } \\
\text { analgesia }\end{array}$ & General anesthesia \\
\hline Responsiveness & $\begin{array}{l}\text { Normal response } \\
\text { to verbal } \\
\text { stimulation }\end{array}$ & $\begin{array}{l}\text { Purposeful response } \\
\text { to verbal or tactile } \\
\text { stimulation }\end{array}$ & $\begin{array}{l}\text { Purposeful response } \\
\text { after repeated or } \\
\text { painful stimulation }\end{array}$ & $\begin{array}{l}\text { Unarousable, even } \\
\text { with painful stimuli }\end{array}$ \\
\hline Airway & Unaffected & $\begin{array}{l}\text { No intervention } \\
\text { required }\end{array}$ & $\begin{array}{l}\text { Intervention may be } \\
\text { required }\end{array}$ & $\begin{array}{l}\text { Intervention often } \\
\text { required }\end{array}$ \\
\hline $\begin{array}{l}\text { Spontaneous } \\
\text { ventilation }\end{array}$ & Unaffected & Adequate & May be inadequate & $\begin{array}{l}\text { Frequently } \\
\text { inadequate }\end{array}$ \\
\hline Cardiac function & Unaffected & Usually maintained & Usually maintained & May be impaired \\
\hline
\end{tabular}

be addressed and relayed to the physician. Finally, the nurse should review the Mallampati score and American Society of Anesthesiologists (ASA) classification (Tables 3, 4); should complications occur, this information will allow for quicker handoff and intervention from anesthesia $[13,14]$.

After arriving at the NIR suite, a baseline set of vital signs including pulse, blood pressure, respiratory rate, and $\mathrm{SaO}_{2}$ should be obtained. At the start of the case and after sedation has been administered, vitals are to be documented every $5 \mathrm{~min}$. In addition, once the patient is sedated, the level of sedation should be charted as well [15]. The provider performing the sedation/anesthesia on the patient should be familiar with the depth of the sedation given to the patient [15]. Sedation levels are noted in the Practice Guidelines set up by the ASA, as seen below (Table 5). By remaining at the patient's bedside, adverse effects from medications for intraprocedural complications can be noticed promptly and reported to the interventionalist. The conscious sedation nurse may be asked to assess the patient's neurologic status throughout the procedure, communicating any changes or differences from baseline examination results.

Postprocedural care may vary from institution to institution, depending on staffing and patient flow. Whether the conscious sedation nurse remains at the patient's bedside, or 
handoff is made to a recovery nurse, the frequency of monitoring does not change. A postprocedural neurologic examination must be completed by the conscious sedation nurse. The interventionalist is made aware of the neurologic examination and is also included in the handoff communication with the recovery nurse. Vital signs are monitored every $15 \mathrm{~min}$ for a total of $30 \mathrm{~min}$. If reversal agents have been required, vital sign monitoring may be extended to $2 \mathrm{~h}$. The patient may then be admitted to the desired unit, or discharged if specified criteria have been met [10]. While discharge criteria are facility specific, in order to be discharged patients should at a minimum have returned to their baseline mental status, have hemodynamic stability, and be able to ambulate, urinate, and tolerate food and drink [11].

Whatever the level of sedation, the responsibility remains the same. The conscious sedation nurse is expected to recognize and respond to hemodynamic changes and medical emergencies. The nurse should have a detailed understanding of anatomy and physiology, cardiac arrhythmias, and the pharmacology and side effects of the medications being administered. With the advanced cardiac life support (ACLS) certification, a nurse should have proficiency in airway management and hemodynamic monitoring [12].

The interventionalist determines the type of anesthesia used during emergency or elective procedures. Typically, if the procedure requires catheters to be entered intracranially, general anesthesia is used. At times, primarily in emergent situations, moderate sedation can be used, depending on the physician's comfort and the patient's cooperation.

\section{Emergency Roles}

Due to the highly acute states of the patient population and the nature of NIR care, unplanned and unforeseen emergencies do occur. These can range from cardiac arrest to vessel perforation resulting in acute hemorrhage in the brain. The NIR nurse needs to be able to act quickly and have tools available for whatever emergency may arrive.

Every NIR suite should have emergency medical equipment available in the room, or in a central core region that is accessible. The crash cart should contain a defibrillator, an Ambu bag, and emergency cardiac medications. Should a code occur, the circulating RN will be responsible for calling the code per the department/hospital policy, obtaining the crash cart, and connecting the patient to the defibrillator. The nurse should also be prepared to perform the role designated by the code leader.

In the case of neurologic emergencies if vessel perforation and intracranial hemorrhage result, equipment needs to be available to address increased ICP and placement of an EVD as quickly as possible. Medications to reverse anticoagulants such as protamine and agents to reduce ICP such as mannitol should be readily available. There should be a daily log or checklist to ensure that a drain, craniotomy kit, and drainage system are present and accessible in the room. During this check, the expiration date and integrity of the kits/trays should be controlled as well. The circulator is responsible for obtaining the equipment and preparing it for the neurosurgeon's arrival. The circulator should also be prepping the drainage system with preservative-free normal saline in preparation for ICP monitoring once the EVD is in place.

\section{Nursing Stroke Care: From the Emergency Department over the Interventional Radiology Laboratory to the Destination after the Procedure}

\section{Staffing Models: In-House versus On-Call}

Staffing levels can and will affect the patient's ability to receive appropriate care in the acute phase. Different staffing models are seen for "regular" working hours compared to "off- 
Table 6. Staffing recommendations

\begin{tabular}{lll}
\hline Discipline & Regular hours & Off-hours \\
\hline Advanced practice RN & In-house & In-house \\
Radiology technologist & In-house & In-house or less than 30 min arrival time to hospital \\
Radiology nurse & In-house & In-house or less than 30 min arrival time to hospital \\
Neurologist & In-house & Telephone, telemedicine, or in person within minutes \\
Interventionalist & In-house & On-call \\
Pharmacist & In-house & In-house \\
\hline
\end{tabular}

RN, registered nurse.

hours." The so-called weekend effect, in addition to admission during off hours such as nights and holidays, can negatively impact mortality and outcome for stroke patients [16-21]. Several studies have been published which look at the effect staffing has on the mortality and functional outcome of stroke patients. During off-hours, patients are noted to wait longer for diagnostic imaging and admission $[17,18]$. An increase in the number of patients eligible for IV alteplase is often seen on the weekend - however, there are decreased odds of receiving the medication on the weekend [16-18]. Even with telemedicine, there is a technological delay when the physician is off site [20].

If there is a need to call in physicians, nurses, and technologists at night, an increase in the time to intra-arterial (IA) alteplase administration is seen [20]. An American study looking at clinical outcomes after intracranial thrombectomy on weekends versus weekdays showed an increase in moderate/severe disability during weekends in non-teaching hospitals [22]. A study from Canada showed that delays are minimized with the presence of an in-house stroke call team 24/7 [21].

Solutions to this staffing dilemma include transferring the patient to a comprehensive stroke center, where there is more consistent staffing on weekends [23]. Ideally there should be a $24 / 7$ stroke coverage at large interventional stroke centers that would include access to stroke specialists, stroke teams, and organized systems of care [19, 23, 24]. To further decrease delays, around-the-clock interventional team coverage is essential and an angiography tray should always be ready for use [21].

A stroke team led by advanced practice nurses has been shown to be efficient, accurate, and safe for treating stroke patients in the emergency department (ED) with a 24-h staffing model [25]. Pharmacists should also be considered part of the care team. The pharmacy resident is able to help determine the inclusion criteria for IV alteplase administration, assist with its administration, and help monitor for adverse effects [26, 27].

Ongoing staffing assessments should be conducted at each site to determine the best regular hours for staffing with consideration that this may not be a traditional 8:00-5:00 schedule. Certified comprehensive stroke centers are required to have an interventionalist available 24/7. Facilities with high numbers of endovascular treatment may also consider $24 / 7$ coverage by the interventionalist or establishing a response time (Table 6).

\section{Continuous Certifications/Safety Requirements for the Neurointerventional Staff}

As in any area of specialty nursing, the NIR nurse is required to maintain certifications and compliance as part of hospital standards. Each nurse must be able to demonstrate competency in performing conscious sedation and radiation safety (including maintenance of the dosimeter badge) through education and a written examination. These examinations are defined and often provided by the institution. The nurse will also be required to maintain a 
Table 7. FAST examination

$\begin{array}{ll}\text { F ... Face } & \text { Ask the person to smile, does one side droop? } \\ \text { A ... Arms } & \text { Ask the person to raise both arms, does one arm drift downward? } \\ \text { S ... Speech } & \text { Ask the person to repeat a simple phrase, is their speech slurred or strange? } \\ \text { T ... Time } & \text { If you observe any of these symptoms call 9-1-1 immediately }\end{array}$

certification in ACLS/basic life support and in use of the NIHSS. This examination is specific to the neurologic patient population cared for in an NIR suite and must be renewed every 2 years. The nurse must provide documentation of the certification for this examination, as well as for the others mentioned above.

POCT performance in the angiography suite also requires competencies and daily quality controls. The nurse will be required to complete a written examination for each POCT device (ACT/VerifyNow) annually. Each device must have a quality control that is run each shift and documented in the designated log. Performing quality checks promptly at the start of each shift, or upon arrival while on-call, will ensure accurate results and decrease delays.

Depending on your institution, continued education specific to stroke may be required. For those centers that are comprehensive stroke centers, the nurse requires at least $8 \mathrm{~h}$ of continuing education in the area of stroke each year [23]. This can be completed through accredited meetings, journals, and lectures.

It should be noted that the RN working in the NIR suite is not certified to operate the angiography equipment. This is restricted to radiology technicians and physicians who have undergone credentialing and certification. An RN would be practicing out of the scope of practice by operating the equipment.

Lastly, as the field of NIR advances, there will be new devices that are approved and become available. Despite the level of interaction with the device, the nurse and technologist are expected to be proficient in the device's function and use. Clinical and sales representatives from the device company will be available to provide training on such devices. A training log should be developed and maintained by the department, documenting that an in-service training has been completed. The log should be readily available for review.

\section{Periprocedural Care of the Patient}

\section{Neurologic Assessment}

Many stroke scales exist with varying levels of validation and reliability. The stroke team will determine the standard expectations for neurologic examination and documentation at your institution. Stroke recognition begins in the prehospital setting, with stroke scales used to accurately identify patients with large-vessel occlusions.

FAST. The Face Arms Speech Time (FAST) examination developed by the American Stroke Association is a quick and easy scale used to identify signs and symptoms of stroke in patients inside or outside the hospital. The FAST examination does not differentiate between smalland large-vessel occlusions [27] (Table 7). It was originally developed to be used for public education campaigns but has also seen an increase in use among in-hospital personnel.

LAMS. Developed for prehospital personnel, the Los Angeles Motor Scale (LAMS) stroke assessment is a validated, widely used tool shown to have good interrater reliability and good correlation with the NIHSS [28] (Table 8). The LAMS is validated to predict the presence of a large-vessel occlusion; a score $\geq 4$ indicates that the likelihood of a large-vessel occlusion is increased 7-fold [28]. 


\begin{tabular}{l|l}
\hline DOI: $10.1159 / 000481541$ & $\begin{array}{l}\text { ( ) 2017 S. Karger AG, Basel } \\
\text { www.karger.com/ine }\end{array}$ \\
\hline
\end{tabular}

Hill et al.: Recommendations for Endovascular Care of Stroke Patients

Table 8. LAMS (Los Angeles Motor Scale)

Table 9. RACE (Rapid Arterial Occlusion Evaluation) scale

\begin{tabular}{ll} 
Facial droop & \\
Absent & 0 \\
Present & 1 \\
Arm drift & \\
Absent & 0 \\
Arm drifts down & 1 \\
Arm falls rapidly & 2 \\
Grip strength & \\
Normal & 0 \\
Weak grip & 1 \\
No grip & 2 \\
\hline
\end{tabular}

$\begin{array}{lr}\text { Face palsy } & \\ \text { Absent } & 0 \\ \text { Mild } & 1 \\ \text { Moderate to severe } & 2 \\ \text { Arm motor impairment } & 0 \\ \quad \text { Normal to mild } & 1 \\ \text { Moderate } & 2 \\ \text { Severe } & \\ \text { Leg motor impairment } & 0 \\ \quad \text { Normal to mild } & 1 \\ \text { Moderate } & 2 \\ \text { Severe } & \\ \text { Head and gaze deviation } & 1 \\ \quad \text { Absent } & \\ \quad \text { Normal } & 0 \\ \text { Aphasia (if right hemisphere) } & 1 \\ \quad \text { Performs both tasks }{ }^{1} \text { correctly } & 2 \\ \quad \text { Performs one task correctly } & \\ \text { Performs neither task correctly } & 0 \\ \text { Agnosia (if left hemisphere) } & \\ \quad \text { Recognizes his/her arm and the impairment } & 1 \\ \quad \text { Does not recognize his/her arm or the impairment } & 1 \\ \text { Does not recognize his/her arm nor the impairment } & 2\end{array}$

Score 0-9. ${ }^{1}$ Task 1: "Close your eyes." Task 2: "Make a fist." ${ }^{2}$ Ask the patient (1) while showing them the paretic arm, "Whose arm is this?" (2) "Can you lift both arms and clap?"

RACE. The Rapid Arterial Occlusion Evaluation (RACE) scale is the first validated tool for detection of large-vessel occlusion in the prehospital setting [29] (Table 9). A score $\geq 5$ on the RACE scale has an $85 \%$ sensitivity and $65 \%$ specificity in detecting large-vessel arterial occlusions [29]. The RACE scale has a similar predictive value to the NIHSS [29].

C-STAT. Originally developed as the Cincinnati Prehospital Stroke Severity Scale (CPSSS), the name was changed to Cincinnati-Stroke Triage Assessment Tool (C-STAT) in order to prevent confusion with the Cincinnati Prehospital Stroke Scale (CPSS) (Table 10). The C-STAT was developed to predict the presence of severe acute ischemic stroke or large-vessel occlusion. A score $\geq 2$ on the C-STAT has an $83 \%$ sensitivity and $40 \%$ specificity in detecting large-vessel arterial occlusions [30].

ESI. The Emergency Severity Index (ESI) is a tool that can be used to help triage patients upon arrival at the ED [31]. The ESI uses a $0-5$ scoring system, with 0 being the most severe 
Table 10. C-STAT (Cincinnati-Stroke Triage Assessment Tool)

Fig. 1. ESI (Emergency Severity Index). m, months; $\mathrm{y}$, years; HR, heart rate; RR, respiratory rate.
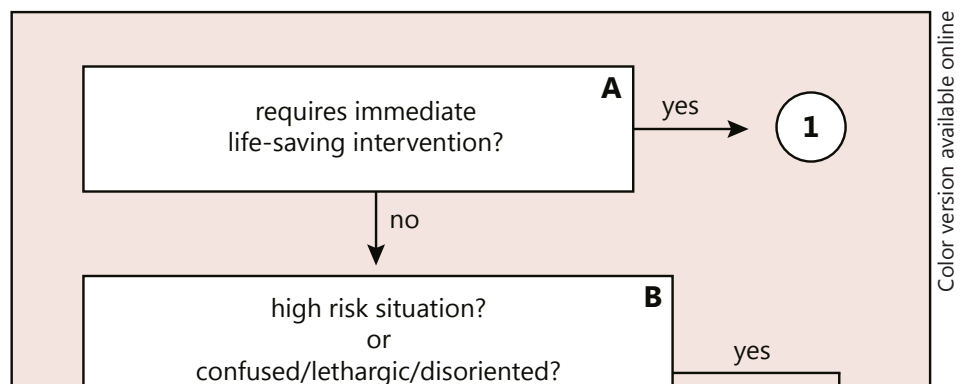

confused/lethargic/disoriented?

severe pain/distress?

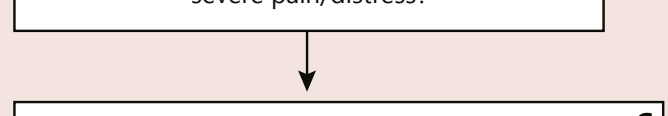

how many different resources are needed?

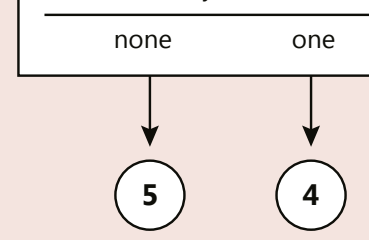

many

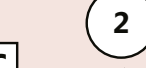
yes
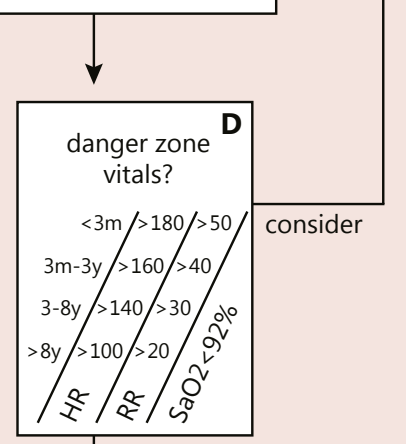

no

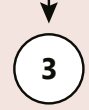

(c) ESI Triage Research Team, 2004

injury or illness (Fig. 1). The ESI would place all stroke patients at level 2, which means "needs immediate assessment" [31]. For all patients with an acute presentation of acute neurologic symptoms, there should be specialized checklists, protocols, and other tools in place for the triage nurse to identify stroke patients and initiate a stroke alert [27]. The initial patient assessment in the ED should focus on assessing the ABCs and vital signs and making a neurologic assessment [27]. All patients presenting with stroke symptoms should have cardiac monitoring in place [27]. The triage nurse or charge nurse in the ED should assume the responsibility to initiate a stroke alert based on the patient's presenting conditions, i.e., 


\section{Interventional Neurology}

\begin{tabular}{l|l}
\hline \multicolumn{2}{l|}{ Intervent Neurol 2018;7:65-90 } \\
\hline DOI: 10.1159/000481541 & $\begin{array}{l}\text { C 2017 S. Karger AG, Basel } \\
\text { www.karger.com/ine }\end{array}$ \\
\hline
\end{tabular}

Hill et al.: Recommendations for Endovascular Care of Stroke Patients

Table 11. NIHSS (National Institutes of Health Stroke Scale)

\begin{tabular}{|c|c|c|c|}
\hline \multicolumn{2}{|c|}{ Category } & \multirow{2}{*}{$\begin{array}{l}\text { Description } \\
\text { 0: Alert; keenly responsive } \\
\text { 1: Not alert; but arousable by minor stimulation to obey, answer or respond } \\
\text { 2: Not alert; requires repeated stimulation to attend, or is obtunded and requires strong or } \\
\text { painful stimulation to make movements } \\
\text { 3: Responds only with reflex motor or autonomic effects or totally unresponsive, flaccid, } \\
\text { and areflexic }\end{array}$} & \multirow[t]{2}{*}{ Score } \\
\hline $1 \mathrm{a}$ & $\begin{array}{l}\text { Level of } \\
\text { consciousness }\end{array}$ & & \\
\hline $1 \mathrm{~b}$ & $\begin{array}{l}\text { Level of } \\
\text { consciousness, } \\
\text { questions }\end{array}$ & $\begin{array}{l}\text { 0: Answers both questions correctly } \\
\text { 1: Answers one question correctly } \\
\text { 2: Answers neither question correctly }\end{array}$ & \\
\hline $1 \mathrm{c}$ & $\begin{array}{l}\text { Level of } \\
\text { consciousness, } \\
\text { commands }\end{array}$ & $\begin{array}{l}\text { 0: Performs both tasks correctly } \\
\text { 1: Performs one task correctly } \\
\text { 2: Performs neither task correctly }\end{array}$ & \\
\hline 2 & Best gaze & $\begin{array}{l}\text { 0: Normal } \\
\text { 1: Partial gaze palsy; gaze is abnormal in one or both eyes, but forced deviation or total gaze } \\
\text { paresis is not present } \\
\text { 2: Forced deviation; or total gaze paresis is not overcome by the oculocephalic maneuver }\end{array}$ & \\
\hline 3 & Visual & $\begin{array}{l}\text { 0: No visual loss } \\
\text { 1: Partial hemianopia } \\
\text { 2: Complete hemianopia } \\
\text { 3: Bilateral hemianopia (blind including cortical blindness) }\end{array}$ & \\
\hline 4 & Facial palsy & $\begin{array}{l}\text { 0: Normal symmetrical movements } \\
\text { 1: Minor paralysis (flattened nasolabial fold, asymmetry on smiling) } \\
\text { 2: Partial paralysis (total or near-total paralysis of lower face) } \\
\text { 3: Complete paralysis of one or both sides (absence of facial movement in the } \\
\text { upper and lower face) }\end{array}$ & \\
\hline $\begin{array}{l}5 \\
5 a \\
5 b\end{array}$ & $\begin{array}{l}\text { Motor arm } \\
\text { Left arm } \\
\text { Right arm }\end{array}$ & $\begin{array}{l}\text { 0: No drift; limb holds } 90 \text { (or } 45 \text { ) degrees for full } 10 \mathrm{~s} \\
\text { 1: Drift; limb holds } 90 \text { (or } 45 \text { ) degrees but drifts down before full } 10 \mathrm{~s} \text {; does not hit bed or } \\
\text { other support } \\
\text { 2: Some effort against gravity; limb cannot get to or maintain (if cued) } 90 \text { (or } 45 \text { ) degrees, } \\
\text { drifts down to bed, but has some effort against gravity } \\
\text { 3: No effort against gravity; limb falls } \\
\text { 4: No movement } \\
\text { UN: Amputation or joint fusion }\end{array}$ & Right \\
\hline $\begin{array}{l}6 \\
6 \mathrm{a} \\
6 \mathrm{~b}\end{array}$ & $\begin{array}{l}\text { Motor leg } \\
\text { Left leg } \\
\text { Right leg }\end{array}$ & $\begin{array}{l}\text { 0: No drift; leg holds } 30 \text {-degree position for full } 5 \mathrm{~s} \\
\text { 1: Drift; leg falls by the end of the } 5 \text {-s period but does not hit the bed } \\
\text { 2: Some effort against gravity; leg falls to bed by } 5 \mathrm{~s} \text { but has some effort against gravity } \\
\text { 3: No effort against gravity; leg falls to bed immediately } \\
\text { 4: No movement } \\
\text { UN: Amputation or joint fusion }\end{array}$ & Right: \\
\hline 7 & Limb ataxia & $\begin{array}{l}\text { 0: Absent } \\
\text { 1: Present in one limb } \\
\text { 2: Present in two limbs } \\
\text { UN: Amputation or joint fusion }\end{array}$ & \\
\hline 8 & Sensory & $\begin{array}{l}\text { 0: Normal, no sensory loss } \\
\text { 1: Mild-to-moderate sensory loss; patient feels pinprick is less sharp or is dull on the affected } \\
\text { side; or there is a loss of superficial pain with pinprick, but patient is aware of being touched } \\
\text { 2: Severe or total sensory loss; patient is not aware of being touched in the face, arm, and leg }\end{array}$ & \\
\hline
\end{tabular}


Table 11 (continued)

\begin{tabular}{lll}
\hline Category & Description \\
\hline 9 & Best language & 0: No aphasia; normal \\
1: Mild-to-moderate aphasia; some obvious loss of fluency or facility of comprehension, \\
without significant limitation on ideas expressed or form of expression. Reduction of speech \\
and/or comprehension, however, makes conversation about provided materials difficult or \\
impossible. For example, in conversation about provided materials, examiner can identify \\
picture or naming card content from patient's response \\
2: Severe aphasia; all communication is through fragmentary expression; great need for \\
inference, questioning, and guessing by the listener. Range of information that can be \\
exchanged is limited; listener carries burden of communication. Examiner cannot identify \\
materials provided from patient response \\
3: Mute, global aphasia; no usable speech or auditory comprehension
\end{tabular}

whether IV alteplase is an option versus endovascular therapy. The stroke alerts can be titled differently in order to help the team anticipate the needs of the patient arriving. The patient designated as a stroke alert should receive q15-min vital sign and neurologic checks for at least $1 \mathrm{~h}$ in order to evaluate the neurologic status.

NIHSS. The NIHSS is a valid and reliable tool used to determine stroke severity and treatment options and to predict patient outcomes. It is commonly used in both clinical and research trial settings as a standardized quantitative assessment of neurologic deficit severity. The NIHSS should be completed within the first 10 min of the stroke patient's arrival at the ED $[23,32,33]$. The NIHSS is useful across all levels of healthcare provision and presents a way to standardize assessment with high interrater reliability and to quantify the patient's baseline assessment and subsequent assessments [27, 32, 33] (Table 11). Posterior circulation strokes can be missed when the NIHSS alone is used and a score of 0 does not rule out that a stroke is occurring [34]. It is recommended that NIHSS users undergo formal training and certification through the American Stroke Association or similar organizations who offer certification [32]. A competent practitioner should use the NIHSS before and after an intervention is performed, and upon admission to the intensive care unit; several abbreviated versions of the NIHSS exist and should be used for further neurologic assessments [32].

MEND. The Miami Emergency Neurologic Deficit (MEND) examination includes assessment items that will identify posterior stroke symptoms often missed by the NIHSS [34, 35] (Table 12). The MEND examination can be used by prehospital and in-hospital personnel and includes a scoring component to quantify the severity of the neurologic deficit [35]. The ability to use this examination across all aspects of stroke care is beneficial for improving communication throughout the continuum of care. The MEND examination was developed by the University of Miami and is taught as part of their Advanced Stroke Life Support Course. 
Table 12. MEND (Miami Emergency Neurologic Deficit) Examination

\begin{tabular}{|c|c|c|}
\hline $\begin{array}{l}\text { Mental status } \\
\text { Level of consciousness }\end{array}$ & $\begin{array}{l}\text { A: Alert } \\
\text { V: Alert to verbal } \\
\text { P: Alert to painful } \\
\text { U: Unresponsive }\end{array}$ & $\square$ Abnormal \\
\hline Questions & Age and year (any incorrect is abnormal) & $\square$ Abnormal \\
\hline Speech & $\begin{array}{l}\text { Repeat a phrase: "You can't teach an old dog } \\
\text { new tricks." }\end{array}$ & $\square$ Abnormal \\
\hline Commands & Close, open eyes & $\square$ Abnormal \\
\hline $\begin{array}{l}\text { Cranial nerves } \\
\text { Facial droop }\end{array}$ & Show teeth or smile & $\begin{array}{l}\square \text { Abnormal left } \\
\square \text { Abnormal right }\end{array}$ \\
\hline Visual fields & Four quadrants & $\begin{array}{l}\square \text { Abnormal left } \\
\square \text { Abnormal right }\end{array}$ \\
\hline Horizontal gaze & Side to side & $\begin{array}{l}\square \text { Abnormal left } \\
\square \text { Abnormal right }\end{array}$ \\
\hline $\begin{array}{l}\text { Limbs } \\
\text { Drift - arm }\end{array}$ & Close eyes, hold arms out & $\begin{array}{l}\square \text { Abnormal left } \\
\square \text { Abnormal right }\end{array}$ \\
\hline Drift - leg & Open eyes, lift each leg separately & $\begin{array}{l}\square \text { Abnormal left } \\
\square \text { Abnormal right }\end{array}$ \\
\hline Sensory - arm & Close eyes and touch, pinch & $\begin{array}{l}\square \text { Abnormal left } \\
\square \text { Abnormal right }\end{array}$ \\
\hline Sensory - leg & Close eyes and touch, pinch & $\begin{array}{l}\square \text { Abnormal left } \\
\square \text { Abnormal right }\end{array}$ \\
\hline Coordination - arm & Finger-nose & $\begin{array}{l}\square \text { Abnormal left } \\
\square \text { Abnormal right }\end{array}$ \\
\hline Coordination - leg & Heel-shin & $\begin{array}{l}\square \text { Abnormal left } \\
\square \text { Abnormal right }\end{array}$ \\
\hline
\end{tabular}

Total score (0-22, each abnormal = 1 point $)$ :

Organizations should pick an assessment or triage scale and train their personnel accordingly. The use of multiple scales at an organization is not recommended. An overview of the different neurologic assessments or tools is presented in Table 13.

\section{Frequency of Examinations and Vital Sign Assessments}

Neurologic and vital sign assessments should occur at a minimum every $30 \mathrm{~min}$ for patients waiting to receive endovascular treatment [25, 32] (Table 14). Blood pressure measurement during the reperfusion therapy procedure is recommended every 5 min [25]. Postprocedural vital sign monitoring may follow the same guidelines as reperfusion treatment with an alteplase infusion: q15 min for $2 \mathrm{~h}$, q30 min for $6 \mathrm{~h}$, and q1 h for $16 \mathrm{~h}$.

\section{Consent}

IV alteplase is a recommended standard of care for acute ischemic stroke patients who meet inclusion and exclusion criteria, and, therefore, signed informed consent is recom- 
Table 13. Summary of neurologic assessment scales

\begin{tabular}{llll}
\hline Scale & $\begin{array}{l}\text { Developed for } \\
\text { prehospital } \\
\text { personnel }\end{array}$ & $\begin{array}{l}\text { Developed for } \\
\text { in-hospital } \\
\text { personnel }\end{array}$ & $\begin{array}{l}\text { Detects } \\
\text { large-vessel } \\
\text { occlusion }\end{array}$ \\
\hline FAST & $\mathrm{x}$ & $\mathrm{x}$ & \\
LAMS & $\mathrm{x}$ & & $\mathrm{x}$ \\
RACE & $\mathrm{x}$ & $\mathrm{x}$ & $\mathrm{x}$ \\
NIHSS & & $\mathrm{x}$ & $\mathrm{x}$ \\
MEND & $\mathrm{x}$ & & $?$ \\
C-STAT & $\mathrm{x}$ & $\mathrm{x}$ \\
\hline
\end{tabular}

Table 14. Monitoring frequency

\begin{tabular}{lll}
\hline Procedure monitoring & Assessment & Frequency \\
\hline Preprocedural & Vital signs, neurologic check & q30 min \\
Intraprocedural & Vital signs ${ }^{1}$, neurologic check as able & q5 min \\
Postprocedural & Vital signs, neurologic check & q15 min for 30 min \\
& Vascular access site & q15 min for $1 \mathrm{~h}, \mathrm{q} 30$ min for 1 h, q1 h for 4 h \\
\hline
\end{tabular}

${ }^{1}$ Cardiac monitor rate/rhythm, noninvasive blood pressure, respiratory rate, $\mathrm{O}_{2}$ saturation, ventilation status, and depth of sedation.

mended but not required. The process of obtaining consent can be tricky when different cultures and languages are involved in comprehension of the process [36]. If the patient is unable to consent, the assumption of consent for IV alteplase for ischemic stroke has been endorsed by the American Academy of Neurology and the American Heart Association/ American Stroke Association [37]. A study published in 2014 found that older adults were no less likely to desire IV thrombolytic therapy when unable to consent then when asked directly; however, assumption of consent should only be applied when informed consent cannot be obtained [37]. Endovascular treatment is now considered a standard of care by the American Stroke Association for large-vessel occlusions and should follow the same consent process as IV alteplase [6].

In an acute situation, every attempt at obtaining either verbal or written consent should be made prior to the intervention. In non-acute situations, verbal or written consent should be obtained prior to the intervention. Treatment should not be withheld in an emergency because of an inability to obtain consent. After every attempt has been made to gain consent from the patient or family, the provider should clearly document the reason consent was not obtained and the need for emergency treatment. This documentation is an important component of comprehensive stroke monitoring and review for certification.

Time-Out

Before any cerebral endovascular procedure, a standardized time-out should be performed [38]. The time-out should involve the following personnel: the individual performing the procedure, the anesthesia provider (if applicable), the nurse, the radiology technologist, and any other personnel participating in the procedure from the beginning [39]. During the time-out, the care team should actively communicate and agree on the following: - $\quad$ Correct patient identity 
- $\quad$ Correct site

- Procedure to be performed

- Allergy

- Creatinine, INR, and platelet count

- Review of medication list

If the patient requires a second procedure and the personnel in the room changes, a second time-out should be performed [39]. Documentation of the time-out should be made according to the organization's standards and policy [39]. The time-out is an important component of comprehensive stroke monitoring and review for certification.

\section{Air Embolism}

Air embolism is a complication that may occur in the following situations [40]:

- Air in pressurized flush bags connected to arterial lines

- Bubbles in syringes that form when contrast or saline are drawn up

- Disconnected stopcocks or loose rotating hemostatic valves that may allow air to enter the circulatory system when blood pressure falls

- Rupture of balloons that have not been adequately degassed prior to inflation

- Air bubbles in contrast injectors

- Air bubbles in flush tubing that connects pressure bags to arterial lines

Quick identification is important for treatment of air embolism. Treatment includes [40]:

- Termination of the connection between the offending arterial line and the patient

- Elevating the patient's blood pressure

- Ventilation with $100 \%$ oxygen

- Hyperbaric oxygen therapy

\section{Groin or Sheath Postmanagement}

Postprocedural care and attention to the access site is the responsibility of the NIR nurse, fellow, and NIR physician team. Although the femoral approach is the most common and preferred method of accessing cerebral vessels, the vasculature of patients may impede the ability to use the femoral artery. When the patient has a tortuous vasculature in the lower extremities, the radial and/or brachial arteries are often considered a good alternative to the femoral artery [41]. If the vertebral artery is the target vessel, the radial approach will be beneficial for quicker access [42].

\section{Compression/Closure Device for the Femoral Approach}

At the conclusion of the procedure, sheath removal and access site management must be addressed. In the past, manual compression for 15-20 min was the gold standard, until vascular closure devices became available [43, 44]. Vascular closure devices have been found to be safe and effective at achieving hemostasis and decreasing the duration of bed rest required [43-46]. Vascular closure devices work by three different methods: suture closure, collagen plugs, and staples/clips [44]. If a vascular closure device cannot be used, manual compression should be considered [44]. The ACT level should be checked prior to sheath removal, and mechanical pressure held for $60 \mathrm{~min}$ or manual pressure for $30 \mathrm{~min}$. Complications may occur with any hemostatic technique; they are outlined in Table 15 [45]. Complications with the femoral access approach are outlined in Table $16[42,45]$.

\section{Radial Approach}

The radial artery approach for endovascular therapy has advantages and disadvantages, which are detailed in Table 17 [41, 42]. Hemostasis after radial approach is achieved using two different methods: manual compression or a compression device [42]. For patients who 
Table 15. Complications associated with femoral device selection

\begin{tabular}{ll}
\hline Device & Complication \\
\hline Compression & $\begin{array}{l}\text { Deep venous thrombosis from femoral vein compression and stasis } \\
\text { Potential for pulmonary embolism related to deep venous thrombosis } \\
\text { Limb ischemia }\end{array}$ \\
\hline Suture & $\begin{array}{l}\text { Laceration of the femoral artery by the foot pedals } \\
\text { Partial dissection of the posterior wall by the foot pedals; abrupt or subacute } \\
\text { femoral artery closure } \\
\text { Infection }\end{array}$ \\
\hline Collagen plug & $\begin{array}{l}\text { Anchor embolization } \\
\text { Intra-arterial deposition of the collagen plug } \\
\text { Malalignment of the anchor - cessation of blood flow }\end{array}$ \\
\hline Clip & Risk of capture of the lateral wall of the femoral artery \\
& Oozing at the insertion point from the tissue track \\
\hline
\end{tabular}

are not on anticoagulant therapy, 10 min of manual compression is usually recommended to achieve hemostasis [42]. For patients who are receiving anticoagulants, use of a compression device for $2 \mathrm{~h}$ may be necessary to achieve hemostasis [42].

\section{Sheath Removal}

Sheath removal should be performed by specially trained personnel. It is equally important for the bedside nurse caring for the patient after the endovascular intervention to understand what complications to assess for and how to assess the puncture site. The frequency of vascular access assessment should be included in the postprocedural order set and mirror the neurologic and vital sign assessments.

\section{Early Ambulation}

There are many opinions regarding early ambulation, with general agreement that the earlier the patient is able to ambulate, the fewer complications they will experience. Several studies looked at sheath size, mode of hemostasis achievement, and ambulation time. Some older studies recommended 4-6 h of bed rest, while more recent studies have found that ambulation $2-4 \mathrm{~h}$ after sheath removal is safe $[47,48]$ (Table 18).

\section{Dressing Type}

The use of pressure dressings after sheath removal was common; however, a recent study showed a decreased risk of complications when a transparent dressing is used [49]. If manual compression is the closure method, a pressure dressing is reasonable; if a collagen plug or the clip closure method is used, a transparent dressing will result in fewer complications.

\section{Effective Transitioning of Healthcare for Stroke Patients}

The transfer of a stroke patient's imminent healthcare responsibility from one department to another, as well as from one healthcare provider to another, highly impacts the success and outcomes for the neurovascular patient. Ineffective communication has been proven to contribute to $20-24 \%$ of medical errors, as well as to $43 \%$ of researched malpractice issues. 
Table 16. Complication management: femoral access approach [42, 45]

\begin{tabular}{|c|c|c|}
\hline Complication & Clinical finding & Treatment \\
\hline $\begin{array}{l}\text { Retroperitoneal } \\
\text { hemorrhage }\end{array}$ & $\begin{array}{l}\text { Hypovolemia } \\
\text { Hypotension } \\
\text { Decreased hematocrit } \\
\text { Flank pain }\end{array}$ & $\begin{array}{l}\text { Hydration } \\
\text { Serial blood cell counts } \\
\text { Prolonged bed rest } \\
\text { Holding anticoagulants/antiplatelet agents } \\
\text { Blood transfusion } \\
\text { Surgical evacuation (if severe) }\end{array}$ \\
\hline Pseudoaneurysm & $\begin{array}{l}\text { Painful pulsatile mass } \\
\text { New bruit } \\
\text { Groin pain or burning } \\
\text { Swelling at groin site (confirmed by } \\
\text { ultrasonography) }\end{array}$ & $\begin{array}{l}\text { May close spontaneously } \\
\text { Prolonged bed rest } \\
\text { Close monitoring } \\
\text { Cessation of anticoagulation } \\
\text { Ultrasound-guided compression (if large) } \\
\text { Surgical intervention (if large) } \\
\text { Ultrasound-guided thrombin injection (if large) }\end{array}$ \\
\hline $\begin{array}{l}\text { Arteriovenous } \\
\text { fistula }\end{array}$ & $\begin{array}{l}\text { Usually asymptomatic } \\
\text { High-output congestive heart failure } \\
\text { Palpable thrill } \\
\text { Audible bruit (confirmed by } \\
\text { ultrasonography) }\end{array}$ & $\begin{array}{l}\text { May resolve spontaneously } \\
\text { Ultrasound-guided compression } \\
\text { Surgical repair }\end{array}$ \\
\hline Arterial occlusion & $\begin{array}{l}\text { Leg paresthesia, pain, pallor, } \\
\text { pulselessness, cold }\end{array}$ & $\begin{array}{l}\text { Treatment dependent on location, size, and } \\
\text { patient's ability to tolerate ischemia } \\
\text { Small thromboemboli in well-perfused arterial } \\
\text { areas may undergo spontaneous lysis } \\
\text { Large thromboemboli may require } \\
\text { thromboembolectomy, surgery, and/or } \\
\text { thrombolytic agents } \\
\text { Distal embolic protection devices may be } \\
\text { placed if necessary }\end{array}$ \\
\hline $\begin{array}{l}\text { Femoral } \\
\text { neuropathy }\end{array}$ & $\begin{array}{l}\text { Pain, tingling at groin site } \\
\text { Numbness at site or down leg } \\
\text { Difficulty moving leg } \\
\text { Leg weakness } \\
\text { Decreased patellar tendon reflex }\end{array}$ & $\begin{array}{l}\text { Identification and treatment at the source } \\
\text { Treatment of symptoms } \\
\text { Physical therapy }\end{array}$ \\
\hline Infection & $\begin{array}{l}\text { Pain, fever, erythema, swelling, } \\
\text { purulent drainage at access point }\end{array}$ & $\begin{array}{l}\text { Treatment of symptoms } \\
\text { Antibiotics }\end{array}$ \\
\hline
\end{tabular}

It is also known that communication breakdowns are the primary root cause of more than $60 \%$ of the 2,000 sentinel events analyzed by The Joint Commission (TJC) [50]. As a result of TJC-released patient safety data, in 2006 TJC required and released a National Patient Safety Goal aimed at improving the effectiveness of caregiver communication [51].

Handoff involves the transfer of essential information when the responsibility for patient care shifts from one healthcare provider to another. When handoffs are effective, there is a seamless transition of critical information that results in improved continuity of patient care [50]. The most important function of safe handoffs is information processing, i.e., making sure that essential data are transferred for patient safety [50]. The use of structured tools for handoffs, as well as bedside reports and rounds, are recommended. A model for standardizing handoffs has the potential to result in improvement of patient care [52]. 
Table 17. Summary of the radial artery approach $[41,42]$

\begin{tabular}{|c|c|}
\hline Advantages & Disadvantages \\
\hline Easy hemostasis & Large learning curve \\
\hline Patient is able to ambulate immediately & Increased X-ray exposure \\
\hline $\begin{array}{l}\text { No need to stop antiplatelets or anticoagulants } \\
\text { prior to the procedure }\end{array}$ & More difficult to catheterize \\
\hline Easier vertebral artery access & Increase in pain for the patient and radial artery spasm \\
\hline
\end{tabular}

Table 18. Ambulation recommendations after groin closure

\begin{tabular}{ll}
\hline Closure method & Time to safe ambulation \\
\hline Compression & $4-6 \mathrm{~h}$ \\
Suture & $4.5 \mathrm{~h}$ \\
Collagen plug & $2.2 \mathrm{~h}$ \\
Clip & $2.71 \mathrm{~h}$ \\
\hline
\end{tabular}

\section{Handoff Models}

(1) SBAR: Situation, Background, Assessment, and Recommendation

(2) Six Sigma - Define, Measure, Analyze, Improve, and Control [53]

\section{Who Is Involved in Handoffs?}

After the patient has arrived at your facility, it is the responsibility of the acute stroke response team to communicate to patient providers the emergent plan of care for the stroke patient. If available, the acute stroke advanced practice provider (APP) is the core communicator responsible for delivering care in the ED, ensuring effective communication with the nurses and healthcare providers in the ED, following the patient through the emergent treatment period, and communicating with the neurologist, interventionalist, and admitting hospitalists. The acute stroke APP also communicates with, and delivers the patient to, the critical care unit or step-down unit after mechanical thrombectomy or alteplase administration. The APP performs the handoff at the bedside to the admitting unit's bedside nurse. Both the critical care nurse and the stroke response APP concurrently complete an NIHSS assessment to adequately understand the patient's neurologic examination results. In the absence of APPs, a stroke response team RN (trained in acute stroke care) may be utilized to fulfill the above role. Some facilities already utilize neurocritical care (NCC) RNs to help with this role.

Examples of personnel involved in the stroke process handoff:

- Stroke network neurologist, transfer center RN

- Acute stroke response team, advanced practice nurse

- Neurologist, neurointerventionalist, hospitalist - admitting physician

- $\quad$ Nurses of each unit (ED, NIR, NCC, stroke unit, and operating room)

- APP NCC/neurointensivist

\section{What Information Is Involved in Handoffs?}

Consistent information is necessary for adequate communication and handoff for this high-risk patient population. Examples of required information to adequately transfer care and provide effective care for the stroke patient are the following:

- $\quad$ LKW (last known well) 
- $\quad$ NIHSS score and neurologic deficits

- Allergies

- Medications given

- Anticoagulant/antiplatelet use

- $\quad$ Procedures done (alteplase, interventional radiology, etc.)

- Treatment and future plan of care

- Any complications

- Code status

- Family contact phone number

\section{Time Parameters (Goals) and Quality Metrics to Collect}

Stroke remains a major healthcare problem affecting over 795,000 Americans each year. Stroke is also a contributing cause of functional impairments in individuals, leading to a high number of patients requiring an institutional or skilled level of care [54]. Time from symptom onset to start of treatment is one of the most important data points in stroke care; thus, the overall speed of the revascularization process is an important and appropriate measure. It is estimated that for every 30 -min delay in time to revascularization there is a $10 \%$ decrease in the likelihood of a good outcome of endovascular reperfusion therapy [55].

Endovascular therapy for both urgent and non-urgent neurologic conditions is often available at comprehensive stroke centers. Primary stroke centers may possess resources but often lack the patient volumes and around-the-clock resources necessary to pursue a comprehensive stroke center certification. To receive the designation of comprehensive stroke center, a certification must be obtained from an approved credentialing body.

There are three main certifying bodies for hospital stroke certification; this includes both primary stroke centers and comprehensive stroke centers, as well as the newest designation, acute stroke-ready hospitals. The certifying bodies are: TJC, the Healthcare Facilities Accreditation Program (HFAP), and DNV • GL Healthcare (DNV). The following are descriptions of these certifying bodies:

The HFAP mandates that comprehensive stroke centers provide care for complex stroke patients. Their infrastructure includes advanced treatments in key areas such as neurology, neurosurgery, and neuroradiology. Hospitals with accreditation from another organization may apply for stroke certification. Appropriately qualified clinicians conduct the certification review, and the certification is for a 3-year period, with a mid-cycle review at 18 months. HFAP certification requires all comprehensive stroke centers to provide quality care in the following interventional capabilities: carotid endarterectomy, stenting, IA reperfusion, endovascular ablation, etc. [56].

DNV, a certifying body for comprehensive stroke centers, encompasses the full spectrum of stroke care - diagnosis, treatment, rehabilitation, and education - and establishes clear metrics to evaluate outcomes. Comprehensive stroke centers are typically the largest and best-equipped hospitals in a given geographical area able to treat any kind of stroke presentation or stroke complication. DNV introduced its disease-specific standards and certification program for comprehensive stroke centers following the guidelines set forth by the Brain Attack Coalition and the American Stroke Association for treatment of the most serious stroke events [57].

With guidance from the Brain Attack Coalition, TJC initially developed a certification for primary stroke centers in 2003 and then developed an advanced certification for comprehensive stroke centers in 2012. Comprehensive stroke center institutions are hospitals that have specific abilities to receive and treat the most complex stroke cases including acute ischemic, intracerebral, and subarachnoid hemorrhage. TJC, with collaboration from the American Heart Association/American Stroke Association, has maintained a unique rela- 
tionship, established in 2003 to promote the provision of excellent stroke care in hospitals all across the USA. The goal of establishing this advanced level of certification is to recognize the significant resources, staff, and training that are necessary for the treatment of complex stroke cases. In 2015, the acute stroke ready level of stroke certification also became available. We also anticipate that, over time, states, municipalities, and regions will develop a formal referral stroke system of care so that the most complicated cases will be identified, transferred, and treated at the centers best equipped to provide this kind of specialized care [57].

Centers can choose any certifying institution, and must meet the specific requirement of that agency in order to be certified. All the certifying bodies discussed above require a comprehensive stroke center to provide high-quality and time-efficient care for their stroke patient population. In order to capture endovascular treatment-specific stroke outcomes, metrics are collected, reviewed, and analyzed by each institution and reported to the comprehensive stroke center-certifying bodies. The following are measures that are examples of data capture for reporting [57].

\section{Specific to TJC Comprehensive Stroke Centers: Door to Needle Puncture}

Included population:

- Patients discharged with ICD-10-CM Principle Diagnosis Codes for Ischemic Stroke

- Patients with documented thrombolytic infusion therapy or mechanical endovascular reperfusion therapy

Excluded population:

- Patients less than 18 years of age

- Patients who have a length of stay more than 120 days

- Patients admitted for elective carotid intervention

Rationale for Measure Collection. Timely recanalization of an occluded intracerebral artery is a strong predictor of improved functional outcome and reduced mortality in patients with an acute ischemic stroke [55]. Trials of IA lytic agents and mechanical revascularization devices have historically required start of treatment as long as 6-8 $\mathrm{h}$ for anterior circulation strokes of the middle cerebral artery, with extended times from symptom onset for vertebrobasilar occlusions. At this time, administration of IV tPA within 3-4.5 h of the time last known well remains the recommended first-line approach [6]. However, the short therapeutic window and low rates of recanalization with IV tPA therapy have prompted investigation into alternative approaches via IA infusion of a thrombolytic drug or mechanical recanalization with clot thrombectomy. These other treatments are a consideration for patients in whom IV alteplase fails or is considered likely to fail, who are excluded from IV alteplase treatment, and/or who present with large-vessel occlusion that can be detected directly with brain imaging (noncontrast CT, CT angiography, or magnetic resonance angiography) or indirectly with an NIHSS score greater than 10 [57].

\section{Specific Data That Need to Be Documented during the Procedure}

- (A) Documentation of the date and time of arrival of the patient at your hospital

- (B) LKW documentation

- (C) NIHSS score documentation (if possible)

- (D) Documentation of INR and blood sugar, pressure, and platelets

- (E) Documentation of code status

- (F) Documentation of pre-modified Rankin Scale score

- (G) Documentation of the decision time for the vascular and interventional radiology procedure

- $(\mathrm{H})$ Documentation of scanning utilized to make the decision for the vascular and interventional radiology procedure 
Table 19. An example of an EPIC template

\begin{tabular}{|c|c|c|}
\hline Time & Event & Details \\
\hline 10:51 p.m. & In Facility & Pre-Proc: Arrived \\
\hline 11:43 p.m. & In Pre-Procedure & Pre-Proc: Pre Procedure \\
\hline 11:43 p.m. & Pre-Procedure Complete & Pre-Proc: Pre Procedure \\
\hline 11:43 p.m. & In Room & Intra-proc: Procedure \\
\hline 11:45 p.m. & Patient ID & ID band present and verified. Family is in the lobby \\
\hline 11:45 p.m. & Pre-procedure Verification & $\begin{array}{l}\text { Pre-Procedure verifications performed: consent signed, pulse oximetry/capnography monitoring } \\
\text { in place, H\&P on chart and updated and labs reviewed }\end{array}$ \\
\hline 11:55 p.m. & Pulses & The DP pulses are 2+ bilaterally; The PT pulses are 2+ bilaterally \\
\hline 11:55 p.m. & Neuro Assessment & $\begin{array}{l}\text { Level of Consciousness: Alert; Orientation: } \times 3 \text {; Speech: Clear; Tongue deviation: Midline; Pupil } \\
\text { Size: } 3 \mathrm{~mm} \text { bilateral; Pupil Reaction: Brisk; Motor function assessment: Hand grasp Right greater } \\
\text { than Left, Pedal push/pull Right greater than Left }\end{array}$ \\
\hline 11:55 p.m. & Cardiac Assessment & Cardiac Regularity: Regular; Heart Sounds: S1, S2 \\
\hline 11:55 p.m. & Respiratory Assessment & Respiratory Pattern: Regular; Bilateral Breath Sounds: Clear \\
\hline 11:55 p.m. & XXXXXXXXX, MD - In & Role: Primary Service: Interventional Radiology (Panel 1) \\
\hline 12:01 a.m. & XXXXXXXXX, TECHNOLOGIST - In & Role: Radiology Technologist \\
\hline 12:05 a.m. & Physician Paged & \\
\hline 12:05 a.m. & XXXXXXXXX, TECHNOLOGIST - In & Role: Radiology Technologist \\
\hline 12:10 a.m. & Verified & Time Out: XXXXXXXX, RN \\
\hline 12:10 a.m. & Procedure Start - VR Neuro Stroke & Physician: XXXXXXXX, MD Service: Interventional Radiology (Panel 1) \\
\hline 12:12 a.m. & Vessel Puncture & No Supply Selected - Accessed site: right femoral artery; Access performed by physician \\
\hline 12:19 a.m. & Site Preparation & Site prepped: bilateral groin; Prepped with: chloraprep and chloraprep; The patient was draped \\
\hline $12: 20$ a.m. & Sheath inserted & Sheath 9 Fr $11 \mathrm{~cm}$ Avanti - Sheath exchanged site: right femoral artery \\
\hline 12:20 a.m. & Guidewire Inserted & Wire 0.035 in $150 \mathrm{~cm}$ Guide Ang - Inserted under fluoro \\
\hline $12: 20$ a.m. & Catheter Inserted & Cath 5 Fr 100 cm Highflow Pigtail Tip \\
\hline $12: 20$ a.m. & Vessel Cannulated & Vessel selected: thoracic aorta \\
\hline $12: 20$ a.m. & Vessel Viewed & Imaging performed of: thoracic aorta; Injection method: power injection \\
\hline $12: 22$ a.m. & Vessel Cannulated & Vessel selected: right common carotid artery \\
\hline 12:23 a.m. & Vessel Viewed & $\begin{array}{l}\text { Imaging performed of: right extracranial circulation and right intracranial circulation; Injection } \\
\text { method: power injection }\end{array}$ \\
\hline 12:25 a.m. & Guidewire Inserted & Wire 0.035 in $145 \mathrm{~cm}$ Guide Tad Ii Tapered - Inserted under fluoro \\
\hline $12: 25$ a.m. & Guidewire Inserted & Wire 0.035 in $115 \mathrm{~cm}$ Loc Extension - Inserted under fluoro \\
\hline $12: 25$ a.m. & Vessel Cannulated & Vessel selected: right internal carotid artery \\
\hline 12:29 a.m. & Guidewire Inserted & Wire 0.014 in Guide Soft Tip Transend Ex - Inserted under fluoro \\
\hline $12: 29$ a.m. & Vessel Cannulated & Vessel selected: right middle cerebral artery \\
\hline 12:31 a.m. & Retriever Inserted & Device $4 \times 40 \mathrm{~mm} 0.021$ in Thrombectomy Solitaire3 Platinum - Retriever device inserted \\
\hline 12:33 a.m. & Times & $\begin{array}{l}\text { Call team paged at: } 23: 34 \text { Call team arrived at: } 23: 35 \text { Neuro Radiologist arrived at: } 23: 55 \text { ED } \\
\text { notified for transport at: 23:44 Decision to intervene made at: } 23: 30 \text { Recannulation time: 01:04 }\end{array}$ \\
\hline 12:38 a.m. & Retriever deployed & Device $4 \times 40$ mm 0.021 Thrombectomy Solitaire3 Platinum - Retriever device deployed \\
\hline $12: 43$ a.m. & Balloon Inflation & Cath 9 Fr 95 cm Balloon Guide Merci - Balloon was inflated \\
\hline 12:44 a.m. & Retriever device removed & Device $4 \times 40 \mathrm{~mm} 0.021$ Thrombectomy Solitaire 3 Platinum - Retriever device removed \\
\hline 12:50 a.m. & Guidewire Inserted & Wire 0.014 in Guide Soft Tip Transend Ex - Inserted under fluoro \\
\hline 12:51 a.m. & Catheter Inserted & Cath Prowler Select Plus Straight \\
\hline $12: 52$ a.m. & Vessel Cannulated & Vessel selected: right middle cerebral artery \\
\hline 12:54 a.m. & Retriever Inserted & Device $4 \times 40 \mathrm{~mm} 0.021$ in Thrombectomy Solitaire 3 Platinum - Retriever device inserted \\
\hline 12:55 a.m. & Retriever deployed & Device $4 \times 40 \mathrm{~mm} 0.021$ in Thrombectomy Solitaire 3 Platinum - Retriever device deployed \\
\hline 01:01 a.m. & Balloon Inflation & Cath 9 Fr 95 cm Balloon Guide Merci - Balloon was inflated \\
\hline 01:01 a.m. & Retriever device removed & Device $4 \times 40 \mathrm{~mm} 0.021$ in Thrombectomy Solitaire 3 Platinum - Retriever device removed \\
\hline 01:04 a.m. & Vessel Viewed & Imaging performed of: right intracranial circulation \\
\hline 01:12 a.m. & Vessel Cannulated & Vessel selected: left common carotid artery \\
\hline 01:12 a.m. & Vessel Viewed & $\begin{array}{l}\text { Imaging performed of: left extracranial circulation and left intracranial circulation; Injection } \\
\text { method: power injection }\end{array}$ \\
\hline 01:15 a.m. & Vessel Cannulated & Vessel selected: left vertebral artery \\
\hline 01:21 a.m. & Closure Device & $\begin{array}{l}\text { Closure } 8 \text { Fr Vip Angioseal - Closure device placed in the right femoral artery; Closure device } \\
\text { deployed by: physician; Closure device successfully deployed }\end{array}$ \\
\hline 01:21 a.m. & Sheath Removed & No Supply Selected - Removed intact \\
\hline 01:22 a.m. & Procedure End - VR Neuro Stroke & Physician: XXXXXXXX, MD Service: Interventional Radiology (Panel 1) \\
\hline 01:22 a.m. & XXXXXXXX, MD - Out & Role: Primary Service: Interventional Radiology (Panel 1) \\
\hline 01:22 a.m. & No In Lab Complications & \\
\hline 01:22 a.m. & Handoff Report Given & To XXXXXXXX, RN in NCC \\
\hline 01:26 a.m. & Pulses & The right DP pulse is $2+$; The right PT pulse is $2+$ \\
\hline 01:26 a.m. & Neuro Assessment & $\begin{array}{l}\text { Level of Consciousness: Alert; Orientation: } \times 3 \text {; Speech: Clear; Motor function assessment: Hand } \\
\text { grasp Right greater than Left, Pedal push/pull Right greater than Left }\end{array}$ \\
\hline 01:27 a.m. & Post TICI Score & TICI score: 3 (Full perfusion with filling of all distal branches) \\
\hline 01:38 a.m. & Fluoro time & Fluoro time $=33.9 \mathrm{~min}$; Total dose $=3,000 \mathrm{mGy}$ \\
\hline 01:39 a.m. & Sedation Times & Sedation start time: 00:04 Sedation end time: 01:39 \\
\hline 01:40 a.m. & Out of Room & Intra-proc \\
\hline
\end{tabular}


Table 20. TJC comprehensive stroke center data collection for stroke (STK) and comprehensive stroke (CSTK) measures

\author{
Total stroke cases \\ Ischemic stroke cases \\ tPA cases \\ Drip and ship tPA cases \\ Intervention procedure cases \\ Stroke no intervention \\ Hemorrhagic stroke cases \\ $\mathrm{ICH}$ \\ $\mathrm{SAH}$ \\ Coil \\ Clip
}

\title{
STK measures - primary stroke center
}

Defect free stroke bundle CMS reported

STK 1 DVT prophylaxis

STK 2 D/C on antithrombotic therapy

STK 3 Patients with atrial fibrillation receiving anticoagulation

STK 4 Thrombolytic therapy administered

STK 5 Antithrombotic by end of hospital day 2

STK 6 Discharged on statin

STK 8 Stroke education

STK 10 Rehabilitation assessed

\section{Comprehensive measure report}

CSTK-01 \% NIHSS reported on ischemic strokes on arrival

CSTK-02 Modified Rankin Scale score at 90 days collected \%

CSTK-03a Severity measurement performed for SAH patients

CSTK-03b Severity measurement performed for ICH patients

CSTK-04 Procoagulation reversal initiated \%

CSTK-05 Hemorrhagic transformation (overall) \%

CSTK-06 Nimodipine treatment initiated \%

CSTK-07 Median time to revascularization (min)

CSTK-08 TICI posttreatment reperfusion grade

\section{Target stroke}

Total stroke alert: volume

Stroke alert: door to lab completed

Stroke alert: EKG order to completed (min)

Stroke alert: CXR order to completed (min)

Stroke alert: door to CT (median/min)

Stroke alert: door to CT read (median/min)

Stroke alert: door to doctor ( $\mathrm{min}$ )

Door to drug: (min) average

Door to stroke team arrival

$\%$ eligible acute stroke receiving tPA 60 min of arrival

$\%$ eligible acute stroke receiving tPA $45 \mathrm{~min}$ of arrival

\section{Procedures}

Decision to VIR (physician ready)

Decision to VIR room staff ready (RN and technologist)

Decision to neurosurgeon ready in OR

Decision to OR room staff ready (RN and technologist)

Cases from ED to OR

\section{Complications}

CEA/CAS symptomatic and asymptomatic stroke or mortality 30 day on sheet 2

Neurocritical care ventric infection per 1,000 line days

Periprocedural complication rate (bolt infection)

Decompressive craniectomy complication rate (infection) 
Table 20 (continued)

\title{
Mortality
}

Stroke (AHRQ) mortality O:E

Ischemic

Hemorrhagic

Subdural/other

\author{
Endovascular complications \\ Endovascular groin complications \\ Endovascular groin complication rate \\ Endovascular recanalization procedure all-cause mortality rate w/i $24 \mathrm{~h}$ \\ Endovascular recanalization procedure complications (symptomatic stroke) w/i $24 \mathrm{~h}$ \\ Diagnostic neuroangiography procedure all-cause mortality rate w/i $24 \mathrm{~h}$ \\ Diagnostic neuroangiography procedure complications (symptomatic stroke) w/i $24 \mathrm{~h}$
}

CMS, Centers for Medicare \& Medicaid Services; DVT, deep vein thrombosis; CXR, chest X-ray; VIR, vascular and interventional radiology; CEA/CAS, carotid endarterectomy/carotid artery stenting.

- (I) Sedation documentation (Aldrete score) before/after the procedure

- (J) Vital sign and neurologic check documentation

- (K) Documentation of the time of groin puncture

- (L) Documentation of all catheters entering and exiting the body, with times documented

- (M) Documentation of the number of passes, with times documented

- (N) Documentation of the IA route of alteplase/mechanical endovascular reperfusion, with date and time of initiation

- (O) Reperfusion grade, time of reperfusion

- (P) Documentation of the site of occlusion (artery, distal, or proximal)

Documentation of the door-to-needle time is required by all certifying bodies.

\section{TICI Posttreatment Reperfusion Grade}

Description. Ischemic stroke patients with a posttreatment TICI reperfusion grade of 2B or higher in the vascular territory beyond the target arterial occlusion at the end of treatment with IA thrombolytic (tPA) therapy and/or mechanical endovascular reperfusion therapy are assessed. The TICI reperfusion grade is used to measure cerebral reperfusion. There are four results of scoring: 0 , no perfusion; 1 , perfusion past the initial occlusion, but no distal branch filling; 2a, partial filling of occluded territory $<50 \%$; $2 \mathrm{~b}$, partial filling of occluded territory $>50 \%$; 2c, near-complete reperfusion with slow flow in distal cortical branches or presence of distal cortical emboli; and 3, full perfusion with filling of all distal branches [57, 58].

Rationale for Measure Collection. TICI grading is used to measure cerebral reperfusion and provide adequate documentation of the outcome of the patient [57]. Other key components of patient data collection can be individualized from each institution's preference to utilize in the quality improvement process. The most important factor in comprehensive stroke care is that the evaluation and initial treatment of patients with stroke should be performed in a timely manner. Organized protocols should be utilized and implemented, as well as organized data collection completed, around the institution's process to ensure efficacy of care. An evaluation of process care points is essential for efficiency. An example of data process collection is presented in Table 19.

\section{Who Collects the Data?}

The required data can be collected under the specific requirements of the individual stroke care institution. For example, it may be collected by the NIR staff in electronic or paper 
format, or can also be included in what has been dictated by the physician to document the procedure and intervention. The data will be collected and analyzed by the stroke quality team and compiled for submission as required. Examples and possibilities of personnel who can serve as data collectors for the organization could include: quality outcome manager/ personnel; personnel of individual departments such as neuroscience, nursing, NIR, or cardiology; stroke outcome manager/staff; or ED outcome manager/staff. Organizations could comprise homegrown databases or templates for maintaining all the data elements required.

Many institutions utilize the "Get with the Guidelines" Web-based data repository maintained by outcome scientists to compile the data required for both comprehensive and primary stroke center certification. This program also allows hospitals to compare their data with similar hospitals and other comprehensive stroke centers. An example of the metrics that are required for both primary and comprehensive stroke center certification by TJC can be seen in Table 20 .

Despite the advances in the recognition and treatment of acute and non-acute neurologic conditions, stroke (all causes) remains the leading cause of disability in the USA and a significant contributor to mortality. The field of neurovascular diagnosis and treatment continues to expand rapidly, and institutions are recognizing the importance of providing this service to patients and families. The benefit for patients has been demonstrated in numerous research publications and is now endorsed by the American Heart Association/American Stroke Association clinical practice guidelines for care of both ischemic and hemorrhagic stroke $[6,8,59]$. The authors of this document have contributed from both personal and professional experience in the field during this time of immense growth. We sincerely hope that your team benefits from this resource.

\section{Acknowledgement}

A special thank-you to Lori Masaro, MSN, CNRN, SCRN, for starting us on this journey. Your leadership passion for neuroscience nursing is unending. Thank you for always being an advocate for nursing and for helping to make the profession amazing.

\section{Disclosure Statement}

The authors have no disclosures and declare no conflict of interests. No funding was received for this paper.

\section{References}

1 Berkhemer OA, Fransen PS, Beumer D, van den Berg LA, Lingsma HF, Yoo AJ, et al; MR CLEAN Investigators: A randomized trial of intraarterial treatment for acute ischemic stroke. N Engl J Med 2015;372:11-20 [published correction in N Engl J Med 2015;372:394].

2 Goyal M, Demchuk AM, Menon BK, Eesa M, Rempel JL, Thornton J, et al; ESCAPE Trial Investigators: Randomized assessment of rapid endovascular treatment of ischemic stroke. N Engl J Med 2015;372:1019-1030.

3 Saver JL, Goyal M, Bonafe A, Diener HC, Levy EI, Pereira VM, et al; SWIFT PRIME Investigators: Stent-retriever thrombectomy after intravenous t-PA versus t-PA alone in stroke. N Engl J Med 2015;372:2285-2295.

4 Campbell BC, Mitchell PJ, Kleinig TJ, Dewey HM, Churilov L, Yassi N, et al; EXTEND-IA Investigators: Endovascular therapy for ischemic stroke with perfusion-imaging selection. N Engl J Med 2015;372:1009-1018.

5 Jovin TG, Chamorro A, Cobo E, de Miquel MA, Molina CA, Rovira A, et al; REVASCAT Trial Investigators: Thrombectomy within 8 hours after symptom onset in ischemic stroke. N Engl J Med 2015;372:2296-2306. 
6 Powers WJ, Derdeyn CP, Biller J, Coffey CS, Hoh BL, Jauch EC, Johnston KC, Johnston SC, Khalessi AA, Kidwell CS, Meschia JF, Ovbiagele B, Yavagal DR; American Heart Association Stroke Council: 2015 American Heart Association/American Stroke Association focused update of the 2013 guidelines for the early management of patients with acute ischemic stroke regarding endovascular treatment: a guideline for healthcare professionals from the American Heart Association/American Stroke Association. Stroke 2015;46:3020-3035.

7 Thompson BG, Brown RD Jr, Amin-Hanjani S, Broderick JP, Cockroft KM, Connolly ES Jr, et al; American Heart Association Stroke Council, Council on Cardiovascular and Stroke Nursing, and Council on Epidemiology and Prevention; American Heart Association; American Stroke Association: Guidelines for the management of patients with unruptured intracranial aneurysms: a guideline for healthcare professionals from the American Heart Association/American Stroke Association. Stroke 2015;46:2368-2400.

8 Connolly ES Jr, Rabinstein AA, Carhuapoma JR, Derdeyn CP, Dion J, Higashida RT, et al; American Heart Association Stroke Council; Council on Cardiovascular Radiology and Intervention; Council on Cardiovascular Nursing; Council on Cardiovascular Surgery and Anesthesia; Council on Clinical Cardiology: Guidelines for the management of aneurysmal subarachnoid hemorrhage: a guideline for healthcare professionals from the American Heart Association/American Stroke Association. Stroke 2012;43:1711-1737.

9 Meschia JF, Bushnell C, Boden-Albala B, Braun LT, Bravata DM, Chaturvedi S, et al; American Heart Association Stroke Council; Council on Cardiovascular and Stroke Nursing; Council on Clinical Cardiology; Council on Functional Genomics and Translational Biology; Council on Hypertension: Guidelines for the primary prevention of stroke: a statement for healthcare professionals from the American Heart Association/American Stroke Association. Stroke 2014;45:3754-3832.

10 Green KL: Clinical practice guideline: moderate sedation and analgesia. Association of Radiologic and Imaging Nursing. 2009. www.arinursing.org.

11 American Academy of Nurse Anesthetists (AANA): Non-anesthesia provider procedural sedation and analgesia. 2016. http://www.aana.com/resources2/professionalpractice/Pages/non-anesthesia-providerprocedural-sedation-and-analgesia.aspx.

12 Lehmann S: The role of the imaging nurse in patients undergoing sedated procedures. 2009. http://www. arinursing.org/practice-guidelines/ARINPSRoleRNUndergoingSedated.pdf.

13 American Society of Anesthesiologists: ASA Physical Status Classification System. 2014. https://www.asahq. org/resources/clinical-information/asa-physical-status-classification-system.

14 Raghavendra LJ: Malampati classification. 2014. http://emedicine.medscape.com/article/2172419-overview.

15 American Society of Anesthesiologists Task Force on Sedation and Analgesia by Non-Anesthesiologists: Practice guidelines for sedation and analgesia by non-anesthesiologists. Anesthesiology 2002;96:1004-1017.

16 McKinney JS, Deng Y, Kasner SE, Kostis JB; Myocardial Infarction Data Acquisition System (MIDAS 15) Study Group: Comprehensive stroke centers overcome the weekend versus weekday gap in stroke treatment and mortality. Stroke 2011;42:2403-2409.

17 Sorita A, Ahmed A, Starr SR, Thompson KR, Reed DA, Dabrh AM, et al: Off-hour presentation and outcomes in patients with acute ischemic stroke: a systematic review and meta-analysis. Eur J Intern Med 2014;25:394-400.

18 Campbell JT, Bray BD, Hoffman AM, Kavanagh SJ, Rudd AG, Tyrrell PJ; Intercollegiate Stroke Working Party: The effect of out of hours presentation with acute stroke on processes of care and outcomes: analysis of data from the Stroke Improvement National Audit Programme (SINAP). PLoS One 2014;9:e87946.

19 Madej-Fermo OP, Staff I, Fortunato G, Abbott L, McCullough LD: Impact of emergency department transitions of care on thrombolytic use in acute ischemic stroke. Stroke 2012;43:1067-1074.

20 Fang K, Churilov L, Weir L, Dong Q, Davis S, Yan B: Thrombolysis for acute ischemic stroke: do patients treated out of hours have a worse outcome? J Stroke Cerebrovasc Dis 2014;23:427-432.

21 Almekhlafi MA, Hockley A, Desai JA, Nambiar V, Mishra S, Volny O, et al: Overcoming the evening/weekend effects on time delays and outcomes of endovascular stroke therapy: the Calgary Stroke Program experience. J Neurointerv Surg 2014;6:729-732.

22 Saad A, Adil MM, Patel V, Owada K, Winningham MJ, Nahab F: Clinical outcomes after thrombectomy for acute ischemic stroke on weekends versus weekdays. J Stroke Cerebrovasc Dis 2014;23:2708-2713.

23 DNV - GL Healthcare: Comprehensive Stroke Center Certification Program - Requirements CSC 2.0. Milford, $\mathrm{DNV} \cdot \mathrm{GL}$ Healthcare.

24 Béjot Y, Aboa-Eboulé C, Jacquin A, Troisgros O, Hervieu M, Durier J, et al: Stroke care organization overcomes the deleterious "weekend effect" on 1-month stroke mortality: a population-based study. Eur J Neurol 2013; 20:1177-1183.

25 Middleton S, Grimley R, Alexandrov A: Triage, treatment, and transfer: evidence-based clinical practice recommendations and models of nursing care for the first $72 \mathrm{~h}$ of admission to hospital for acute stroke. Stroke 2015; 46:e18-e25.

26 McConeghy KW, Winstead PS, Cook AM, Martin CA, Weant KA, Flynn JD: Benefits of a 24-hour inhouse on-call program for pharmacy residents. Am J Health Syst Pharm 2012;69:2160-2164.

27 Lawson C, Gibbons D: Acute stroke management in emergency departments. Emerg Nurse 2009;17:30-34.

28 Nazliel B, Starkman S, Liebeskind DS, Ovbiagele B, Kim D, Sanossian N, et al: A brief prehospital stroke severity scale identifies ischemic stroke patients harboring persisting large arterial occlusions. Stroke 2008;39:22642267.

29 Pérez de la Ossa N, Carrera D, Gorchs M, Querol M, Millán M, et al: Design and validation of a prehospital stroke scale to predict large arterial occlusion: the Rapid Arterial Occlusion Evaluation scale. Stroke 2014;45:87-91. 
30 Katz BS, McMullan JT, Sucharew H, Adeoye O, Broderick JP: Design and validation of a prehospital scale to predict stroke severity: Cincinnati Prehospital Stroke Severity Scale. Stroke 2015;46:1508-1512.

31 Tanabe P, Gimel R, Yarnold PR, Kyriacou DN, Adams JG: Reliability and validity of scores on the Emergency Severity Index version 3. Acad Emerg Med 2004;11:59-65.

32 Summers D, Leonard A, Wentworth D, Saver J, Simpson J, Spiker J, et al: Comprehensive overview of nursing and interdisciplinary care of the acute ischemic stroke patient. Stroke 2009;40:2911-2944.

33 Perry JM, McCabe KK: Recognition and initial management of acute ischemic stroke. Emerg Med Clin North Am 2012;30:637-657.

34 Lever NM, Nyström KV, Schindler JL, Halliday J, Wira C 3rd, Funk M: Missed opportunities for recognition of ischemic stroke in the emergency department. J Emerg Nurs 2013;39:434-439.

35 University of Miami Gordon Center for Research in Medical Education: About the MEND. 2013. http://www. asls.net/mend.

36 Chiong W, Kim AS, Huang IA, Farahany NA, Josephson SA: Testing the presumption of consent to emergency treatment for acute ischemic stroke. JAMA 2014;311:1689-1691.

37 Chiong W, Kim AS, Huang IA, Farahany NA, Josephson SA: Inability to consent does not diminish the desirability of stroke thrombolysis. Ann Neurol 2014;76:296-304.

38 Rolley JX, Davidson PM, Salamonson Y, Fernandez R, Dennison CR: Review of nursing care for patients undergoing percutaneous coronary intervention: a patient journey approach. J Clin Nurs 2009;18:2394-2405.

39 The Joint Commission: The universal protocol for preventing wrong site, wrong procedure, and wrong person surgery. www.jointcommission.org/assets/1/18/UP_Poster1.PDF.

40 Gupta R, Vora N, Thomas A, Crammond D, Roth R, Jovin T, et al: Symptomatic cerebral air embolism during neuro-angiographic procedures: incidence and problem avoidance. Neurocrit Care 2007;7:241-246.

41 Lee DG, Lee DH, Shim JH, Suh DC: Feasibility of the transradial or the transbrachial approach in various neurointerventional procedures. Neurointervention 2015;10:74-81.

42 Layton KF, Kallmes DF, Cloft HJ: The radial artery access site for interventional neuroradiology procedures. AJNR Am J Neuroradiol 2006;27:1151-1154.

43 Hamel WJ: Femoral artery closure after cardiac catheterization. Crit Care Nurse 2009;29:39-46; quiz 47.

44 Lasic Z, Nikolsky E, Kesanakurthy S, Dangas G: Vascular closure devices: a review of their use after invasive procedures. Am J Cardiovasc Drugs 2005;5:185-200.

45 Merriweather N, Sulzbach-Hoke LM: Managing risk of complications at femoral vascular access sites in percutaneous coronary intervention. Crit Care Nurse 2012;32:16-29; quiz first page after 29.

46 Nikolsky E, Mehran R, Halkin A, Aymong ED, Mintz GS, Lasic Z, et al: Vascular complications associated with arteriotomy closure devices in patients undergoing percutaneous coronary procedures: a meta-analysis. J Am Coll Cardiol 2004;44:1200-1209.

47 Tongsai S, Thamlikitkul V: The safety of early versus late ambulation in the management of patients after percutaneous coronary interventions: a meta-analysis. Int J Nurs Stud 2012;49:1084-1090.

48 Mohammady M, Heidari K, Akbari Sari A, Zolfaghari M, Janani L: Early ambulation after diagnostic transfemoral catheterization: a systematic review and meta-analysis. Int J Nurs Stud 2014;51:39-50.

49 McIe S, Petitte T, Pride L, Leeper D, Ostrow CL: Transparent film dressing vs pressure dressing after percutaneous transluminal coronary angiography. Am J Crit Care 2009;18:14-19; quiz 20.

50 Wheeler K: Effective handoff communication. Nursing Crit Care 2015;10:13-15.

51 Friesen MA, White SV, Byers JF: Handoffs: implication for nurses; in Hughes RG (ed): Patient Safety and Quality: An Evidence-Based Handbook for NURSES. Rockville, Agency for Healthcare Research and Quality, 2008, chapter 34.

52 Arora V, Johnson J: A model for building a standardized hand-off protocol. Jt Comm J Qual Patient Saf 2006;32: 646-655.

53 Mistry KP, Jaggers J, Lodge A, Alton M, Mericle JM, Frush KS, Meliones JN: Using Six Sigma ${ }^{\circledR}$ methodology to improve handoff communication in high-risk patients; in Henriksen K, Battles JB, Keyes MA, Grady ML (eds): Advances in Patient Safety: New Directions and Alternative Approaches. Rockville, Agency for Healthcare Research and Quality, 2008, vol3: Performance and Tools. https://www.ncbi.nlm.nih.gov/books/NBK43658/.

54 Taft KA: Raising awareness of hemorrhagic stroke. Nursing made incredibly easy! 2009;7:42-52.

55 Khatri P, Yeatts SD, Mazighi M, Broderick JP, Liebeskind DS, Demchuk AM, et al: Time to angiographic reperfusion and clinical outcome after acute ischaemic stroke: an analysis of data from the Interventional Management of Stroke (IMS III) phase 3 trial. Lancet Neurol 2014;13:567-574.

56 DNV - GL Healthcare: HFAP Stroke Certification Guide Handbook v 1.2 Comprehensive Stroke. 2013. http:// www.DNVglhealthcare.com (accessed 7/24/16).

57 Comprehensive Stroke Performance Measurement Implementation Guide. The Joint Commission Certification Disease Specific Care. 2015. http://www.jointcommission.org/assets/1/6/CSTKReleaseNotes2015July.pdf.

58 Goyal M, Fargen KM, Turk AS, Mocco J, Liebeskind DS, Frei D, et al: 2C or not 2C: defining an improved revascularization grading scale and the need for standardization of angiography outcomes in stroke trial. J Neurointerv Surg 2014;6:83-86.

59 Hemphill JC 3rd, Greenberg SM, Anderson CS, Becker K, Bendok BR, Cushman M, et al: Guideline for the management of spontaneous intracerebral hemorrhage: a guideline for healthcare professionals from the American Heart Association/American Stroke Association. Stroke 2015;46:2032-2060. 